\title{
Effect of different moisture content and triaxial test methods on shear strength characteristics of loess
}

\author{
Yong Wang, ${ }^{1, *}$ Wanli $\mathrm{Xie}^{1}$, and Guohong $\mathrm{Gao}^{2}$ \\ ${ }^{1}$ State Key Laboratory of Continental Dynamics, Department of Geology, Northwest University, Xi'an 710069, China \\ ${ }^{2}$ Department of Earth Science and Engineering, Taiyuan University of Technology, Taiyuan 030024, China
}

\begin{abstract}
This paper discussed the effect of moisture content on shear strength of loess during different confining pressure firstly. The variation law of deformation parameters, i.e. shear strength and secant modulus is analysed in detail. The results show that moisture content is the dominant factor of shear strength of Loess, with the increase of water content, the strength parameters levelled down, and there is a linear relationship between them to a certain extent. Compared with confining pressure, the effect of water content on shear strength is more obvious. In addition, triaxial test under different drainage conditions were carried out, namely, consolidated drained(CD) test and consolidated undrained(CU) test. Results indicate that the shear damage characteristics are similar during the two test methods.
\end{abstract}

\section{Introduction}

Loess is widely distributed in arid and semi-arid areas of the world, especially in the Loess Plateau of China, which covers several provinces, i.e. Sinkiang, Qinghai, Gansu, Ningxia, Shanxi and Shaanxi ${ }^{[1-5]}$. Loess is widely used as subgrade of railways and highways in these regions. However, loess is characterised by strong water sensitivity, this property is also defined as water collapsibility ${ }^{[6-8]}$. The collapsibility of loess is mainly manifested in the decrease of shear strength and macrodeformation with the increase of moisture content ${ }^{[9-12]}$. This property can also cause some problems, such as differential settlement of foundation, landslides and slope instability, resulting in series of damages of infrastructures and loss of human lives to some degree ${ }^{[1,13-14]}$. Additionally, in some engineering problems, such as design of foundation and slope protection, the shear strength of loess has a great influence on the quality of engineering.

According to previous research, the cohesion $(c)$ and friction angle $(\varphi)$ of loess are affected by moisture and dry density ${ }^{[15]}$. Moisture is the dominant factor of loess deformation or failure, the strength and resilient modulus of loess decrease significantly under rainfall conditions, surface water infiltration or groundwater rising [16-17]. There is no linear relationship between moisture content and shear strength of loess, with the change of water content, the strength parameters increase first and then decrease ${ }^{[18-23]}$.

It is worth noting that the shear strength parameters of loess are different with different test methods. For the same group of soil samples, different test conditions, especially when the drainage conditions are different, the results are different ${ }^{[24-25]}$. Therefore, it is very important to study the shear strength of loess under different test methods to get a better understanding of its physical significance, and to correctly select the shear strength index in engineering practice.

This paper characterised the variation of shear strength parameters of loess during triaxial test under different confining pressure. In this study, four groups of remolded loess samples with different moisture content were prepared, the influence of water content on shear strength of loess in triaxial tests under different confining pressures is analysed. Compared the shear strength characteristics of loess in triaxial tests under different drainage conditions, namely consolidation drained(CD) test and consolidation undrained(CU) test. All the results are employed to develop a better understanding the effect of moisture content and test methods on shear strength of loess.

\section{Material and methodology}

\subsection{Sample preparation}

Soil samples were taken from a typical section of loess in Yuci County, which is located in Northwest China. In the field, a suitable excavation site was selected, and a 5meter deep exploration well was used to extract soil samples 5-meter below the ground. The soil samples were cut into cylindrical shape with a diameter of $10 \mathrm{~cm}$ and a height of $20 \mathrm{~cm}$, and then wrapped in a moisture-retaining film and transported to the laboratory. The basic physical and mechanical properties of samples are presented in Table 1.

In order to investigate the effect of moisture content on shear deformation of loess, four groups of soil samples

\footnotetext{
Corresponding author: wangyong0811@,outlook.com
} 
with different water content were set up, which were $15 \%$, $18 \%, 20 \%$ and saturated soil respectively. Considering that the loess in engineering construction is mostly disturbed soil, all the soil sample was crushed and screened by $5 \mathrm{~mm}$. Then the water content was determined according to the test plan. The sample was prepared into a cylindrical sample with a diameter of $61.8 \mathrm{~mm}$ and a height of $120 \mathrm{~mm}$ by means of a mould. The difference in moisture content of the same group of samples shall not exceed $1 \%$, and the difference in density shall not exceed $0.01 \%$; otherwise, the soil sample should be made anew, as shown in Table 2.

Table 1. Basic physical and mechanical properties of loess

\begin{tabular}{|c|c|c|c|c|c|c|c|}
\hline $\begin{array}{c}\text { Dry } \\
\text { density }\end{array}$ & $\begin{array}{c}\text { Natural } \\
\text { density }\end{array}$ & $\begin{array}{c}\text { Moisture } \\
\text { content }\end{array}$ & $\begin{array}{c}\text { void } \\
\text { ratio }\end{array}$ & $\begin{array}{c}\text { Plasticity } \\
\text { limit }\end{array}$ & $\begin{array}{c}\text { Liquid } \\
\text { limit }\end{array}$ & $\begin{array}{c}\text { Plasticity } \\
\text { index }\end{array}$ & Saturation \\
\hline $1.36 \mathrm{~g} / \mathrm{cm}^{3}$ & $1.58 \mathrm{~g} / \mathrm{cm}^{3}$ & $13.4 \%$ & 1.08 & $16.9 \%$ & $27.5 \%$ & 10.6 & $28 \%$ \\
\hline
\end{tabular}

Table 2. Basic physical of loess samples

\begin{tabular}{|c|c|c|c|c|c|c|}
\hline Sample type & $\boldsymbol{\omega}(\mathbf{\%})$ & $\mathrm{G}_{\mathbf{s}}\left(\mathrm{g} / \mathrm{cm}^{3}\right)$ & $\boldsymbol{\rho}_{\mathbf{d}}\left(\mathrm{g} / \mathrm{cm}^{3}\right)$ & $\boldsymbol{e}$ & $\boldsymbol{\omega}_{\mathbf{P}}(\mathbf{\%})$ & $\boldsymbol{\omega}_{\mathbf{L}}(\mathbf{\%})$ \\
\hline \multirow{3}{*}{$\begin{array}{c}\text { Remolded } \\
\text { loess }\end{array}$} & 15 & 2.70 & 1.34 & 1.01 & 16.8 & 27.2 \\
\cline { 2 - 7 } & 18 & 2.70 & 1.36 & 0.99 & 16.9 & 27.5 \\
\cline { 2 - 7 } & 20 & 2.70 & 1.36 & 0.99 & 16.9 & 27.5 \\
\cline { 2 - 7 } & Saturated(32) & 2.70 & 1.35 & 1.00 & 16.7 & 26.8 \\
\hline
\end{tabular}

\subsection{Methodology}

Two types of drainage conditions, namely consolidated drained(CD) shear and consolidated undrained(CU) shear, were adopted to explore the influence of test conditions on the shear characteristics of loess. At the same time, four confining pressure grades were set, which were respectively $50 \mathrm{kPa}, 100 \mathrm{kPa}, 200 \mathrm{kPa}$, and $300 \mathrm{kPa}$ (Table $3)$.

The test was composed of two stages: consolidation and drainage. The consolidation time was set to 4 hours. When the pore water pressure dissipated more than $95 \%$, the consolidation was considered stability and the next shear test can be carried out. The shear rate was set to $0.08 \mathrm{~mm} / \mathrm{min}$. When the deviation stress peaked, it was considered that the sample has been destroyed. If there was no peak value, the shear can stop when the axial strain reached $18 \%{ }^{[26]}$.

After consolidated undrained shear test, about 15 grams of soil were selected from the upper and lower parts of the sample to determine its moisture content. If the difference was less than $0.5 \%$, the test data were considered valid, otherwise the test should be reconducted.

Table 3. Triaxial test program

\begin{tabular}{|c|c|c|c|}
\hline $\begin{array}{c}\text { Specimen } \\
\text { type }\end{array}$ & $\begin{array}{l}\text { Moisture } \\
\text { content }\end{array}$ & $\begin{array}{c}\text { Test } \\
\text { condition }\end{array}$ & $\begin{array}{c}\text { Confining } \\
\text { pressure(kPa) }\end{array}$ \\
\hline \multirow{8}{*}{ Loess } & \multirow{2}{*}{$15 \%$} & $\mathrm{CD}$ & \multirow{2}{*}{$50,100,200,300$} \\
\hline & & $\mathrm{CU}$ & \\
\hline & \multirow{2}{*}{$18 \%$} & $\mathrm{CD}$ & \multirow{2}{*}{$50,100,200,300$} \\
\hline & & $\mathrm{CU}$ & \\
\hline & \multirow{2}{*}{$20 \%$} & $\mathrm{CD}$ & \multirow{2}{*}{$50,100,200,300$} \\
\hline & & $\mathrm{CU}$ & \\
\hline & \multirow{2}{*}{ saturated } & $\mathrm{CD}$ & \multirow{2}{*}{$50,100,200,300$} \\
\hline & & $\mathrm{CU}$ & \\
\hline
\end{tabular}

\section{Results and discussion}

\subsection{Effect of moisture content on shear strength}

As show in Table 1, the plastic limit of the sample is $16.9 \%$, and the water content of the three groups set in the test is greater than the plastic limit, while in one group is less than it, this is to investigate the shear strength of the loess under the condition of different water content. To ensure that the water content of the soil sample remains unchanged in the test process, the method of consolidated undrained (CU) is adopted.

As shown in Fig.1, the deformation characteristics of loess are mainly dominated by confining pressure and moisture content. The stress-strain curve of soil samples with different moisture content present the characteristics of strain softening behaviour under different confining pressure, this trend is obvious under low confining pressure, while the curve eventually levelled off under high confining pressure. It is obvious that when the strain increases to $15 \%$, the deviation failure stress gradually decreases with the increase of water content. For the case of moisture content of $15 \%, 18 \%$ and $20 \%$, the strain softening characteristics of stress-strain curves are similar, and the reduction of deviation stress is not very large. For the case of the soil sample is saturated, the softening characteristic of stress-strain curve is obvious, and the deviation stress of failure decreases sharply.

Fig. 2 shows the shear strength parameters of loess specimens under $\mathrm{CU}$ test. It is indicated that when the moisture content is lower than the plastic limit, the cohesion of loess changes slightly with the water content increases from $15 \%$ to $18 \%$. However, when the moisture content is higher than the plastic limit, the cohesion decreases sharply. Test results show that moisture content seems to have little effect on internal friction angle, which decreases by about 5 degrees with the water content increases from $15 \%$ to saturated condition. 


\subsection{Effect of triaxial test methods on shear strength}

Fig. 3 presents the results of $\mathrm{CD}$ test and $\mathrm{CU}$ test on loess samples. It indicates that shear strength is highly depended on moisture content and confining pressure, when the strain reaches about $5 \%$, the stress-strain curve appears inflection point, and then changes slightly. This inflection

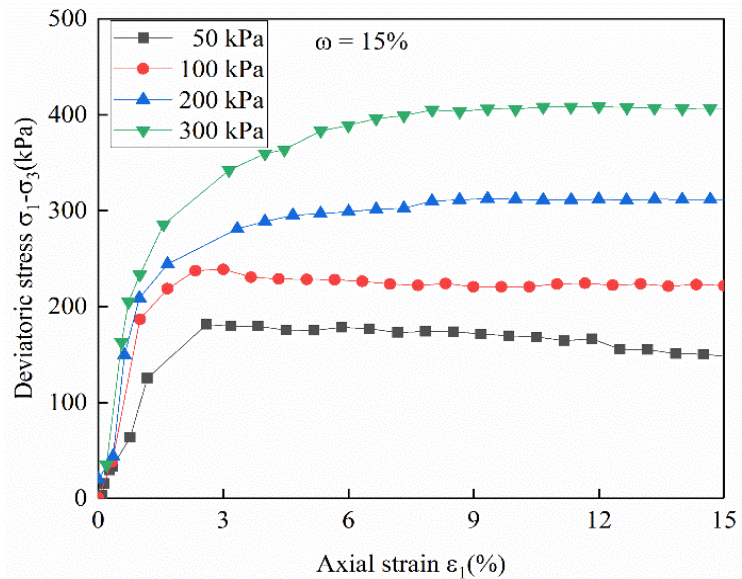

(a)

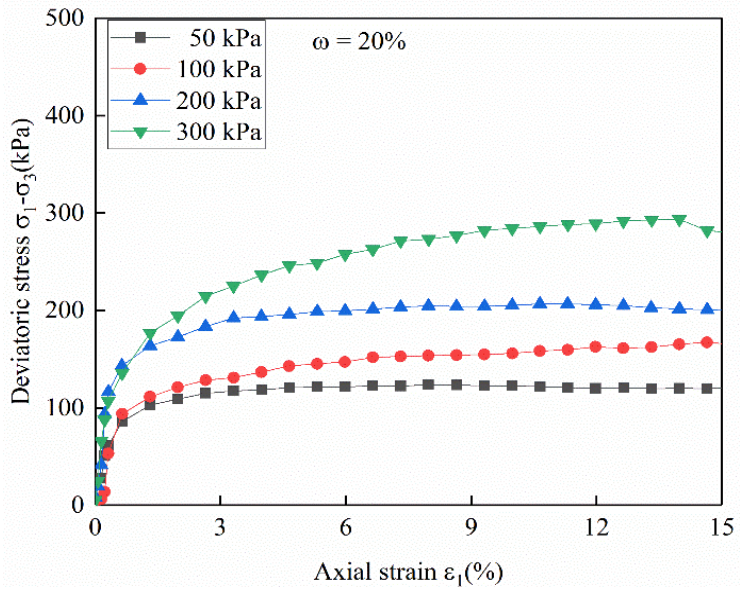

(c) point is also defined as the yield point, which decreases significantly with moisture content ranges from $15 \%$ to saturation. For the case of $\sigma_{3}=50 \mathrm{kPa}$ and $\sigma_{3}=100 \mathrm{kPa}$, the stress-strain curve shows strain softening. While the stress-strain curve shows strain hardening under the condition of $\sigma_{3}=200 \mathrm{kPa}$ and $\sigma_{3}=300 \mathrm{kPa}$ during both the $\mathrm{CU}$ and CD test method. The cohesion of loess is very large when the water content is lower than the plastic limit no matter which method is adopted, while

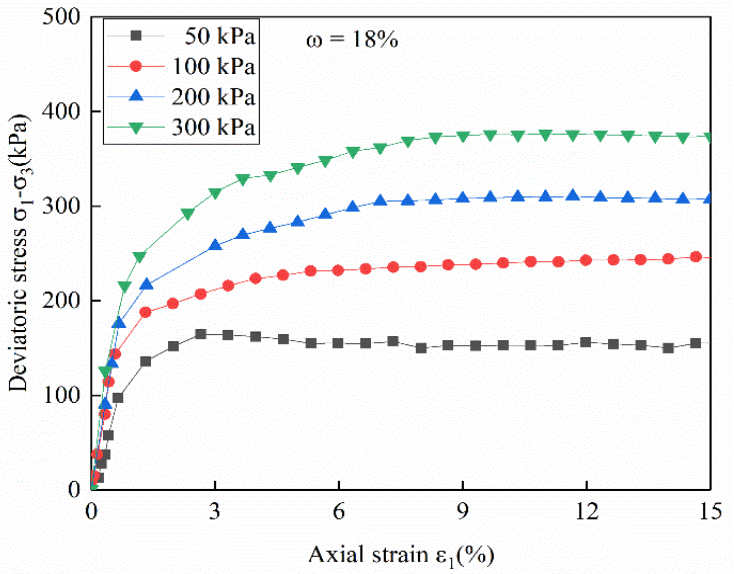

(b)

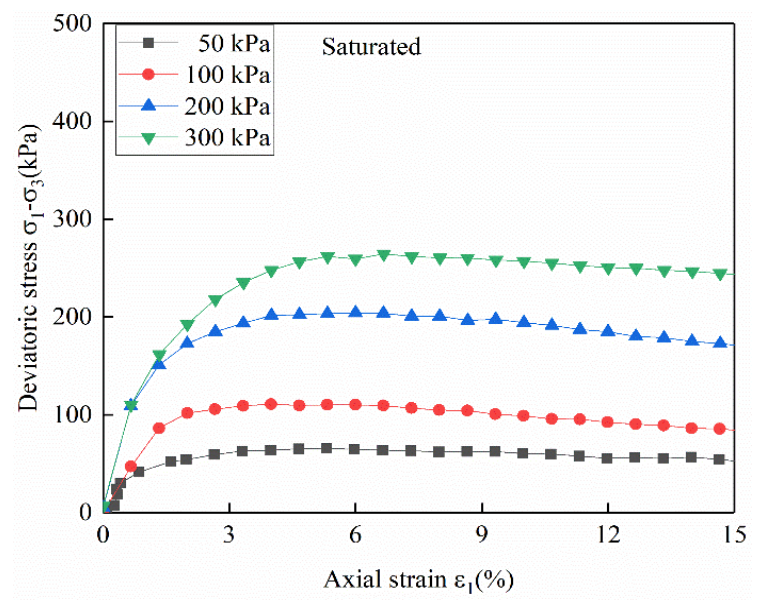

(d)

Fig. 1. Deviatoric stress versus axial strain for the loess samples with the moisture content of (a) 15\%, (b) $18 \%$, (c) $20 \%$ and (d) saturated.

the value decreases significantly when the water content exceeds the plastic limit, as illustrated in Fig. 4. The friction angle shows relative stable during the course of changing of moisture content. The inflection point of stress-strain curve of CU method is always higher than that of CD method (Fig. 3), and the shear strength parameters of loess obtained by $\mathrm{CU}$ method are always larger than that of CD method (Fig. 4). It is suggested that the measured strength parameters are equivalent to the total stress strength under the condition of consolidation and undrained (CU), because the moisture content is not excluded during shearing, there will be a certain excess pore water pressure in the specimens. However, there is no excess pore water pressure in the samples under consolidation drainage (CD) test, and the measured strength can be regarded as an effective shear strength index.

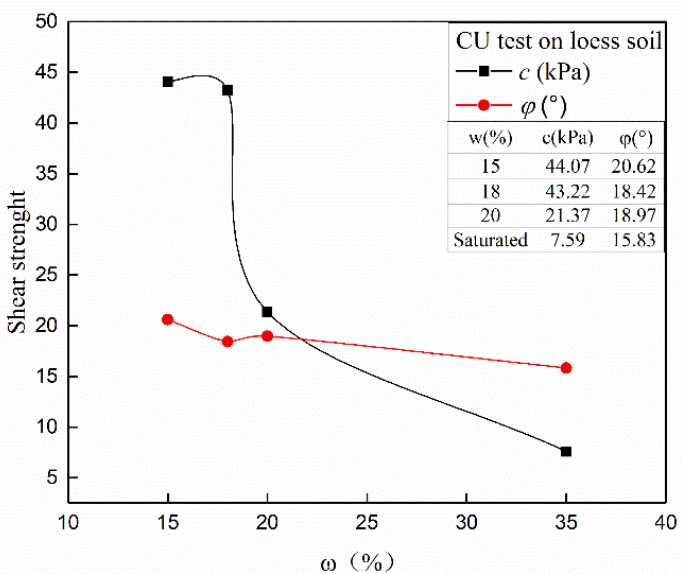

Fig.2. Shear strength with different moisture content conditions of loess specimens. 
According to some previous research, secant modulus $E_{50}$ is a parameter that can well characterize the stress-strain characteristics of loess ${ }^{[27]}$. Therefore, the secant modulus $E_{50}$ of loess specimens can be derived from triaxial test, including CD test and CU test, so that the value can be employed to investigate the influence of

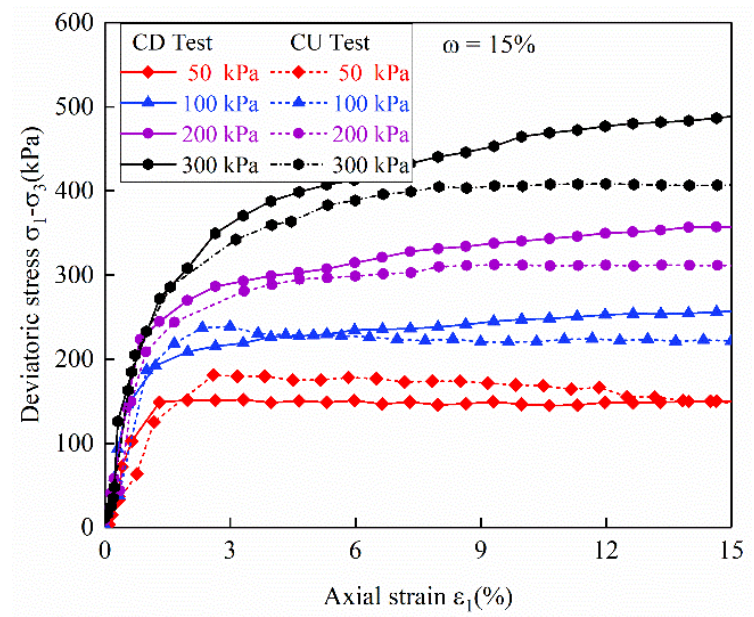

(a)

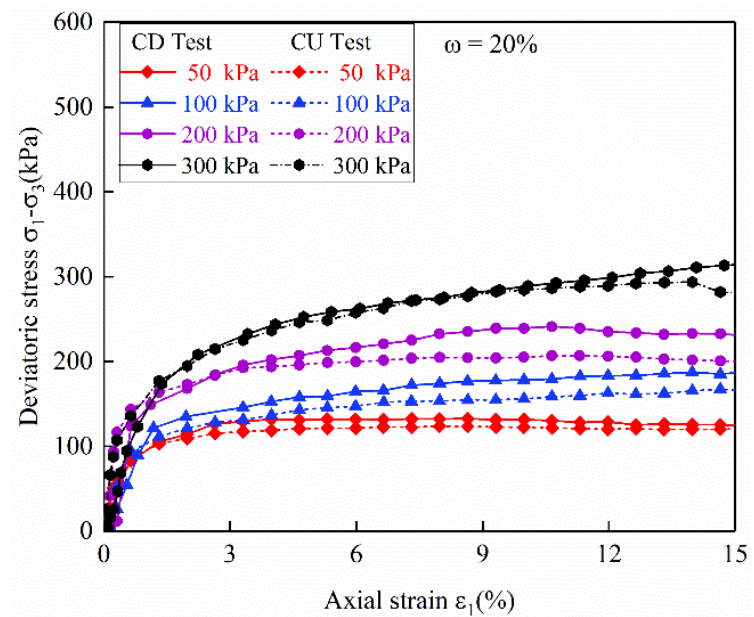

(c) moisture content and confining pressure on shear strength of loess.

Fig. 5 shows the relationship between modulus and confining pressure of triaxial test. It is noteworthy that moisture content has significant effect on the $E_{50}$, for the specimens with moisture content of $15 \%$ and $18 \%$, the

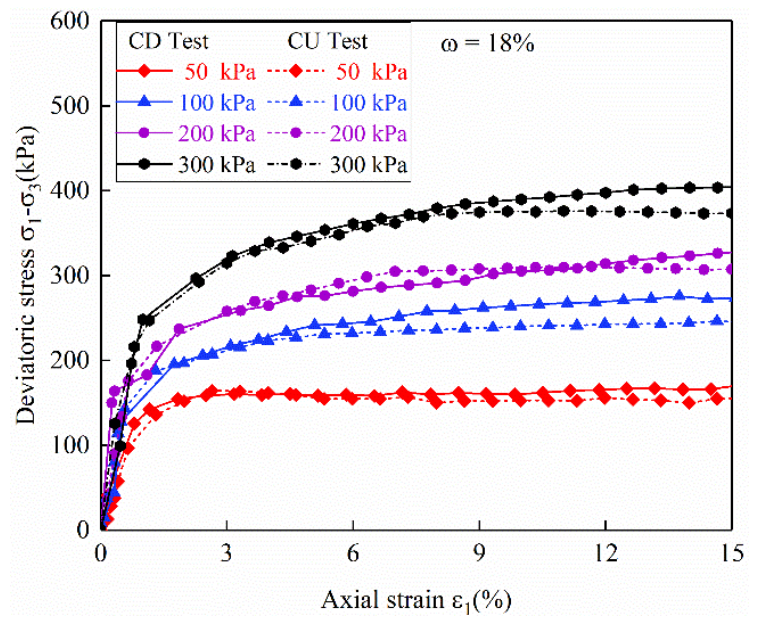

(b)

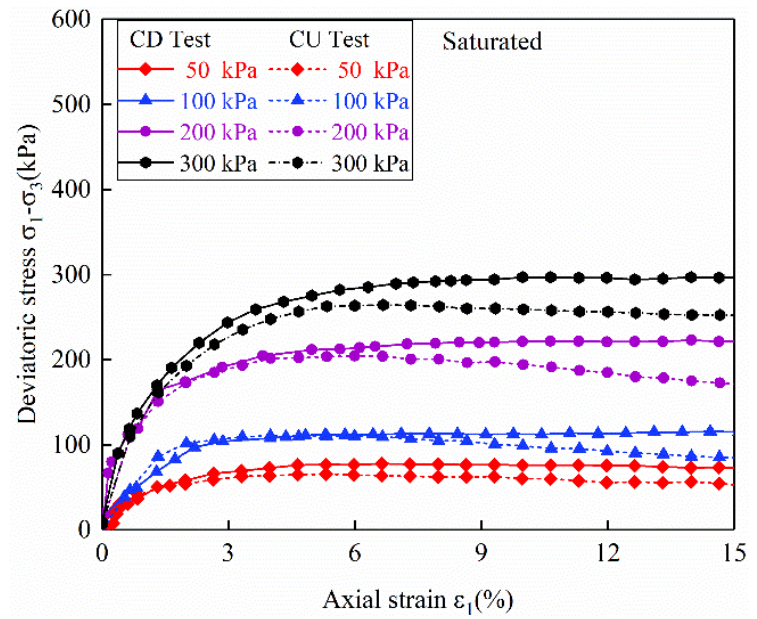

(d)

Fig. 3. Deviatoric stress versus axial strain for the loess samples with the moisture content of (a) $15 \%$, (b) $18 \%$, (c) $20 \%$ and (d) saturated.

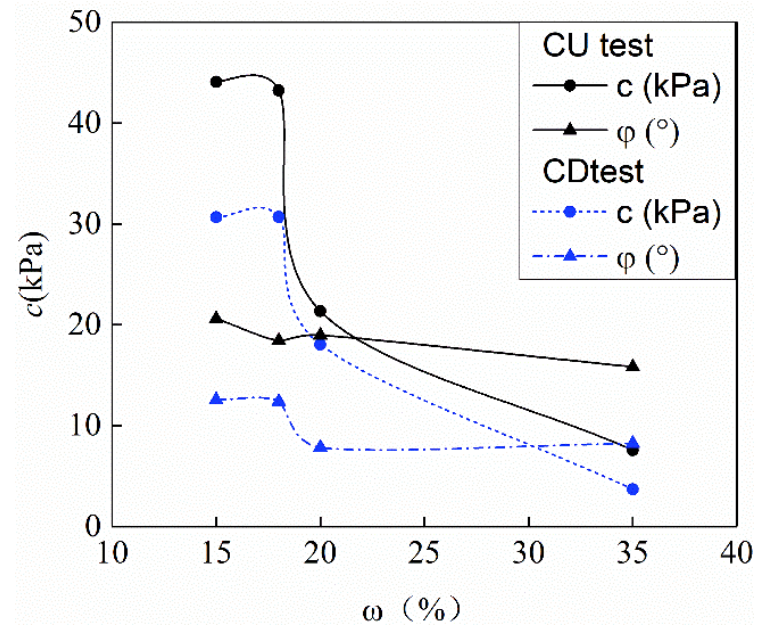

secant modulus increased obviously under both CU test and $\mathrm{CD}$ test, while the secant modulus changed slightly with moisture content of $20 \%$ and saturated condition. The variation of $E_{\mathrm{sec}}$ for samples with moisture content of $20 \%$ shows a constant increase as the rising of confining pressure during the $\mathrm{CD}$ test, while the value of firstly decreased and then keep a rising trend.

The plot in Fig. 5 indicate that for the specimens at moisture content $<20 \%$, the modulus and confining pressure show an approximate linear relationship, when the moisture content of the sample increases. For saturated samples, the modulus hardly changes with the increase of confining pressure, shows a relatively stable trend.

Fig. 4. Shear strength of loess specimens under CU test and CD test. 


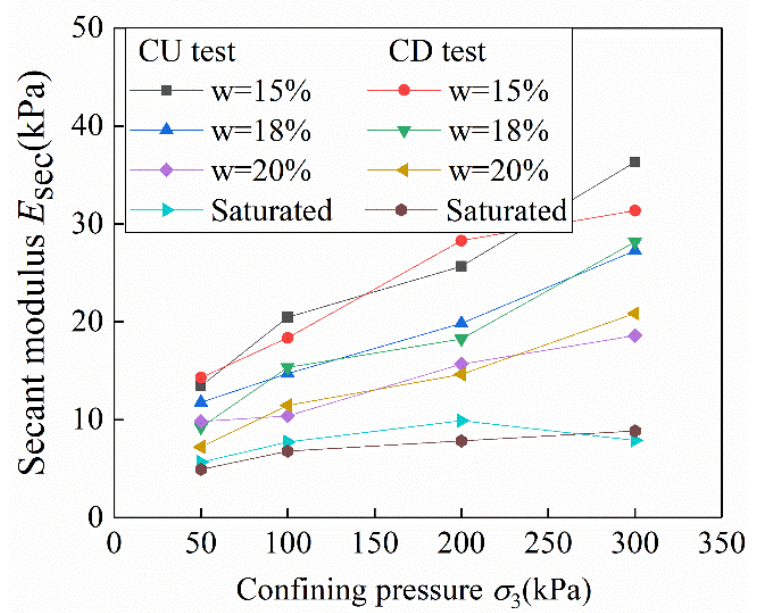

Fig. 5. Secant modulus loess specimens with different moisture content under CU test and CD test.

\section{Conclusion}

This paper compared shear characteristics of loess by triaxial test under different drainage conditions, namely consolidate drained (CD) test and consolidated undrained (CU) test. The data of these two types of test were employed to investigate the effect of moisture content and test methods on loess shear strength. The following conclusions can be drawn based on the results obtained:

(1) Moisture content and confining pressure are the main factors controlling the shear strength of loess. With the increase of moisture content, the stress-strain curve of loess shows obvious strain softening behaviour. The cohesion and decrease slightly with the increase of moisture content, when it is lower than the plastic limit, while when the water content exceeds the plastic limit, the cohesion decreases significantly. The internal friction angle did not decrease significantly with the change of water content.

(2) The stress-strain curves obtained from consolidated drainage(CD) test and consolidated undrained (CU) test show similar characteristics. Similar changes in shear strength parameters of loess under two different test methods. However, strength parameters (i.e. $c$ and $\phi$ ) obtained from consolidated undrained test are larger than consolidated drained test.

(3) Moisture content and confining pressure has a great influence on secant modulus, and there is an approximate linear relationship between them. When the water content is less than $20 \%$, the secant modulus increases significantly with the increase of confining pressure, while the secant modulus changes slightly at the moisture content of saturated condition.

This study was supported by the 2016 Graduate Innovative Talents Training Project (YZZ17199) of Northwest University, China. The corresponding authors is grateful to Mr. Guohong Gao for his help with the sample preparation. The authors are thankful to Dr Jingui Zhao from Taiyuan Univ. of Tech for his advices.

\section{References}

1. E. Derbyshire, T.W. Mellors, Eng. Geol. 25, 2-4,135175 (1988)

2. P.G. Panin, S.N. Timireva, T.D. Morozova, Y.M. Kononov, A.A. Velichko. Catena. 168, 79-101 (2018)

3. IJ. Smalley, K. O'Hara-Dhand, J. Kwong. Catena 117, 2, 100-107 (2014)

4. T.S. Liu, Acta Geol. Sin. 42, 1, 1-18 (1962)

5. T.S. Liu, Loess and the Environment, 481 (1985)

6. A.M. Assallay, CDF Rogers, IJ. Smalley, Eng. Geol. 48, 1-2, 101-15 (1997)

7. G. Gao, Eng. Geol. 25, 2-4, 235-45 (1988)

8. K. M. Rollins, G. W. Rogers. Geotech. Eng. 9, 120, 1533-53 (1994)

9. P. Delage, Y.J. Cui, P. Proc. Int. Conf. on Problematic Soils. Eastern Mediterranean University, Famagusta, N. Cyprus, 1-24 (2005)

10. E. Derbyshire, Earth Sci. Rev. 54, 1-3, 231-260 (2001)

11. T.A. Dijkstra, Quat. Int. 76, 77, 21-28 (2001)

12. P. Li, W. Xie, R. Y.S. Pak, S.K. Vanapallic, Catena 173, 276-288 (2019)

13. S.L. Houston, W.N. Houston, C.E. Zapata, C. Lawrence, Geotech. \& Geol. Eng. 19, 3, 333-55 (2001)

14. Sun JZ, Hydr. \& Eng. Geol., 11, 18-21 (1957) (in Chinese)

15. Y.R. Li, Eng. Geol., 236,4-10 (2018)

16. C. Li, W.D. Deng, X.K. Cui, J. Transp. Sci. Eng. 25, 2, 8-12 (2009)

17. Y.F. Zhou, L.G. Tham, W.M. Yan, F.C. Dai, L. Xu, Eng. Geol. 183, 31-38 (2014)

18. B. Li, T. Miao. Chin, J. Rock Mech. Eng. 25, 5, 10031008 (2006)

19. J. Dang, J. Li. Shui Li Xue Bao, 7, 79-84 (2001)

20. L. Yang, J. Water Resour. Archit. Eng, 8, 3, 163-166 (2010)

21. B. Zhang, H. Yuan, L. Wang, Acta Univ. Agric. Boreali-occidentalis, 22, 1, 54-59 (1994)

22. X. Cheng, MSc Thesis, China University of Geosciences, Wuhan, China (2009)

23. B. Cheng, J. Lu, Constr. Technol. 38, 40-43 (2009)

24. C. Liu, L. Ding, Geol. Prospect. 42, 5, 89-91 (2002)

25. Y. Wang, W. Ni, Z. Yuan, Sci. Technol. Eng., 15, 7, 1671-1815 (2015)

26. ASTM, ASTM D2487-11: Standard Test Method for Classification of Soils for Engineering Purpose (Unified Soil Classification System). ASTM International, West Conshohocken, PA, USA (2011)

27. X.T. Xu, Z.W. Zhou, Y.M. Lai, S.B.Xie, J. Glaciol. Geocryol., 36, 5,1184-1191 (2014) 